\title{
Perancangan Website untuk Desa Mayangan sebagai Media Informasi dan Promosi
}

\author{
Moch. Shulthoni, Ahmad Roziq, Nur Hisamuddin, dan Lilis Yuliati \\ Fakultas Ekonomi dan Bisnis, Universitas Jember. Jalan Kalimantan No 37 Jember, 68121. Indonesia \\ E-mail: shulthon@yahoo.com
}

Keywords: information media, promotion media, tourism

Kata Kunci: media informasi, media promosi, pariwisata

\begin{abstract}
The tourism sector is one of the potential sectors to be developed in modern times, but not all tourist attractions can develop well. One of the factors that cause tourist attractions is the lack of promotion or delivery of information to tourists. The development of the internet is now increasingly advanced so that it is widely used by tourist site managers as a medium of information and promotion. Mayangan Village, Gumukmas District, Jember Regency has the potential to further develop. For this reason, it is necessary to take advantage of the internet by designing the Mayangan village website as a medium for information and promotion. The purpose of this service is to provide knowledge and ability of village officials in managing the Mayangan Village website. The method used is to provide education, training and assistance to create a Mayangan Village Government Website on a continuous basis. The result of this service is designing a website using data collection techniques in the form of interviews, observations, and literature studies. While the software used in designing the Mayangan Village website uses XAMPP, DreamweaverCS 5.5, Adobe Photoshop Photoshop5 and uses programming languages such as HTML, PHP, CSS, Java Script, and JQuery. The implementation of this website is accompanied by blackbox testing. In addition, the website of Mayangan Village, Gumukmas District, Jember Regency was created to inform various natural resources that can be used as tourist destinations. The information presented is expected to make it easier for people to travel. This website is expected to help increase the tourism promotion of Mayangan Village so that it can develop.
\end{abstract}

\section{ABSTRAK}

Sektor pariwisata adalah salah satu sektor potensial untuk dikembangkan di zaman modern, tetapi tidak semua tempat wisata dapat berkembang dengan baik. Salah satu faktor yang menyebabkan tempat wisata adalah kurangnya promosi atau penyampaian informasi kepada wisatawan. Perkembangan internet sekarang semakin maju sehingga banyak digunakan oleh pengelola tempat wisata sebagai media informasi dan promosi. Desa Mayangan, Kecamatan Gumukmas, Kabupaten Jember memiliki potensi untuk lebih berkembang. Untuk alasan ini, perlu memanfaatkan internet dengan merancang situs jaringan desa Mayangan sebagai media untuk informasi dan promosi. Tujuan pengabdian ini adalah memberikan pengetahuan dan kemampuan perangkat desa dalam mengelola website Desa Mayangan. Metode yang dilakukan adalah memberikan pendidikan, pelatihan dan pendampingan untuk pembuatan Website Pemerintah Desa Mayangan secara kontinyu. Hasil pengabdian adalah merancang website menggunakan teknik pengumpulan data dalam bentuk wawancara, observasi, dan studi literatur. Sedangkan perangkat lunak yang digunakan dalam mendesain website Desa 
Mayangan dengan menggunakan XAMPP, DreamweaverCS 5.5, Adobe Photoshop Photoshop5 dan menggunakan bahasa pemrograman seperti HTML, PHP, CSS, Java Script, dan JQuery. Implementasi website ini disertai dengan pengujian blackbox. Selain itu website Desa Mayangan, Kecamatan Gumukmas, Kabupaten Jember dibuat untuk menginformasikan berbagai sumber daya alam yang dapat dijadikan tujuan wisata. Informasi yang disajikan diharapkan memudahkan orang untuk bepergian. Website ini diharapkan dapat membantu meningkatkan promosi Desa Mayangan sebagai desa wisata, sehingga dapat berkembang.

\section{PENDAHULUAN}

Pada zaman era globalisasi ini kemajuan teknologi informasi sangatlah pesat, informasi dapat kita ketahui dengan mudah dengan memanfaatkan fasilitas internet. Semakin banyaknya situs-situs web di internet sebagai wadah informasi secara global yang tidak mengenal waktu dan tempat menjadi suatu hal yang sangat dibutuhkan oleh setiap orang. Tidak hanya pada kalangan bisnis kecil hingga besar yang ingin memasarkan produk dan jasanya secara global, tetapi juga pemerintahan, organisasi, yayasan, dan lembaga individu yang sudah banyak memanfaatkan website untuk mendapatkan kemudahan dalam memberikan layanan dan informasi, serta untuk kemudahan perluasan dan pengembangan bisnis.

Menurut Yolanda dkk (2018) Website adalah salah satu alat media yang tercepat dan terluas untuk mengabarkan informasi. Yolanda dkk (2018) juga menyatakan bahwa Website dapat menyajikan berbagai informasi mengenai profil perusahaan, profil lembaga pendidikan, profil komunitas, kegiatan organisasi, badan usaha pemerintahan, dan media berbagi pengetahuan dan lain-lain. Website tidak hanya dapat digunakan oleh perusahaan atau lembaga besar saja, tetapi banyak digunakan oleh kalangan kecil dan menengah sebagai media promosi yang hemat sekaligus menampilkan profesionalitas, sehingga website menjadi salah satu media yang dapat diandalkan.

Desa Mayangan, yang terletak di Kecamatan Gumukmas, Kabupaten Jember, Provinsi Jawa Timur adalah salah satu desa yang memiliki banyak potensi wisata dan pertanian. Keindahan alam dan budaya masyarakat setempat juga sangat memesona, tetapi tidak banyak orang yang tahu keindahan desa Mayangan ini, sehingga tidak banyak wisatawan yang mengunjungi Desa Mayangan. Pariwisata dan hasil produk di Desa Mayangan akan diinformasikan dan dipromosikan secara daring menggunakan situs web. Informasi potensial di desa jika tersebar luas tentu akan mengundang wisatawan lokal dan regional untuk datang menikmati Desa Mayangan. Informasi yang jelas dan lengkap tentu akan menarik perhatian berbagai pihak dan dapat mempopulerkan desa. Situs web berisi berbagai informasi yang tersedia, pendekatan dalam membuat situs web menggunakan teknik pengumpulan data dalam bentuk wawancara, observasi, dan studi literatur.

Permasalahan yang ditemui di Desa Mayangan adalah belum memiliki alat promosi untuk memperkenalkan potensi dan produk yang dihasilkan dari Desa Mayangan. Layanan belum maksimal bagi penduduk desa karena terbatasnya fasilitas yang dimiliki oleh Desa Mayangan. Pengabdian Desain Situs Web di Desa Mayangan, Kabupaten Gumukmas dibuat dengan tujuan untuk (1) Membantu mempromosikan Desa Mayangan menjadi lebih populer, menjadi lebih ramai dan dapat meningkatkan pendapatan desa; (2) Membantu pejabat desa dan wisatawan lokal dan regional dalam mencari informasi tentang Desa Mayangan, dan (3) Memberikan panduan dan kemudahan kepada wisatawan untuk mengunjungi Desa Mayangan. 


\section{METODE}

Kegiatan ini berlangsung di Kantor Balai Desa Mayangan pada tanggal 11 Oktober sampai dengan 01 November 2019 yang terletak di Desa Mayangan Kecamatan Gumukmas Kabupaten Jember. Target atau sasaran dalam pengabdian pelatihan web ini adalah perangkat desa yang bertindak sebagai operator komputer di Desa Mayangan. Teknis pelaksanaan kegiatan ini antara lain proses pembuatan website mengidentifikasi kebutuhan website yang akan dirancang, perancangan tampilan atau layout web, pengumpulan data-data yang dibutuhkan untuk membangun web Desa, dan melakukan web hosting. Menganalisa kebutuhan pengguna dengan mengenalkan profil Desa Mayangan baik ke dalam Kota jember maupun luar kota Jember. Analisa kebutuhan dasar pembuatan website menggunakan PHP terstruktur dan MySQL.

\section{HASIL DAN PEMBAHASAN}

Desa Mayangan didirikan pada tanggal 8 Oktober 1918, dipimpin oleh seorang Tokoh Masyarakat bernama Mbah Mangku. Pada awalnya sebelum Pak Singosari memerintah di Desa Mayangan, dahulu kala hidup seorang ulama Islam atau Kyai bernama Mbah Mangku, yang dikatakan sebagai orang pertama yang babat di desa ini. Pada saat itu para pemimpin masyarakat membuat keputusan Desa/Musyawarah mengenai pemilihan dan pengangkatan Kepala Desa hingga dua kali pertama karena calon Kepala Desa pada saat itu tidak ada pemaksaan pemilihan Kepala Desa yang gagal. Untuk pemilihan kedua, calon kepala desa masih belum datang, jadi calon kepala desa harus dicari/dijemput. Ternyata calon kepala desa bisa ditemukan sedang memancing di laut. Setelah datang ke tempat pemungutan suara, ditanya oleh Camat, bagaimana mungkin sudah terlambat, calon kepala desa menjawab "Saya dari Mayang (Mencari Ikan)". Dengan pepatah "Mayang" dari calon kepala desa, dalam musyawarah yang menghasilkan 2 (dua) keputusan sebagai berikut: 1) bahwa nama Desa Mayangan diambil dari kata "Mayang", dan 2) Kepala Desa pertama Mayangan ditetapkan sebagai Singosari. Makam Mbah Mangku sekarang terletak di dusun Kalimalang, Desa Mayangan, sebelah timur Kantor Balai Desa Mayangan, sekitar 3,5 Km dari Kantor Desa Mayangan.

Pada tahap awal pembuatan situs web adalah mengidentifikasi kebutuhan situs web yang akan dirancang, mendesain tampilan atau tata letak web, mengumpulkan data yang dibutuhkan untuk membangun web desa, dan melakukan hosting web. Proses ini dilakukan melalui diskusi langsung dengan pejabat desa dan anggota Desa Mayangan untuk memastikan desain web sesuai dengan kebutuhan yang diharapkan. Situs web yang dirancang nantinya dapat dikelola dengan baik oleh otoritas dan diakses secara daring dengan memanfaatkan fasilitas internet yang memadai. Membangun situs web Desa Mayangan dilakukan dalam beberapa tahap (Roziq dkk, 2019):

1. Requirement (Analisa Kebutuhan Pengguna): (a) Mengenalkan profil desa kepada masyarakat baik dalam Jember maupun luar Jember, (b) Mengenalkan potensi wisata alam desa pada wisatawan, (c) Mengenalkan potensi wisata kuliner desa pada penjaja kuliner dalam maupun luar negeri, (d) Mengenalkan produk tertentu seperti: hasil alam dan kerajinan sebagai daya tarik.

2. Analisa Kebutuhan Dasar Pembuatan Website: (a) Bahan pemrograman yang dibutuhkan, (b) PHP juga disebut sebagai pemograman Server Side Programming terstruktur menggunakan Framework Codeigniter (Sibero dalam Supriyanta dan Khairun Nisa, 2015), (c) MySQL atau dibaca "My Sekuel" dengan suatu RDBMS (Relational Database Management System) merupakan aplikasi sistem yang menjalankan fungsi pengolahan data yang telah dipakai dimana-mana oleh Developer Website pada umumnya Domain resmi dari Pemerintah yaitu: 
desa.id atau hosting dari penyedia layanan hosting tertentu (Sibero dalam Sibero dalam Supriyanta dan Khairun Nisa, 2015).

3. Fitur Dan Manfaat

a. Banner dan Slide Banner

Menurut Roziq dkk (2019) Banner merupakan sebuah objek yang biasa digunakan agar dapat menambah daya tarik, memunculkan ciri khas, alat promosi dan juga dapat berperan untuk menonjolkan isi dari Website tersebut.

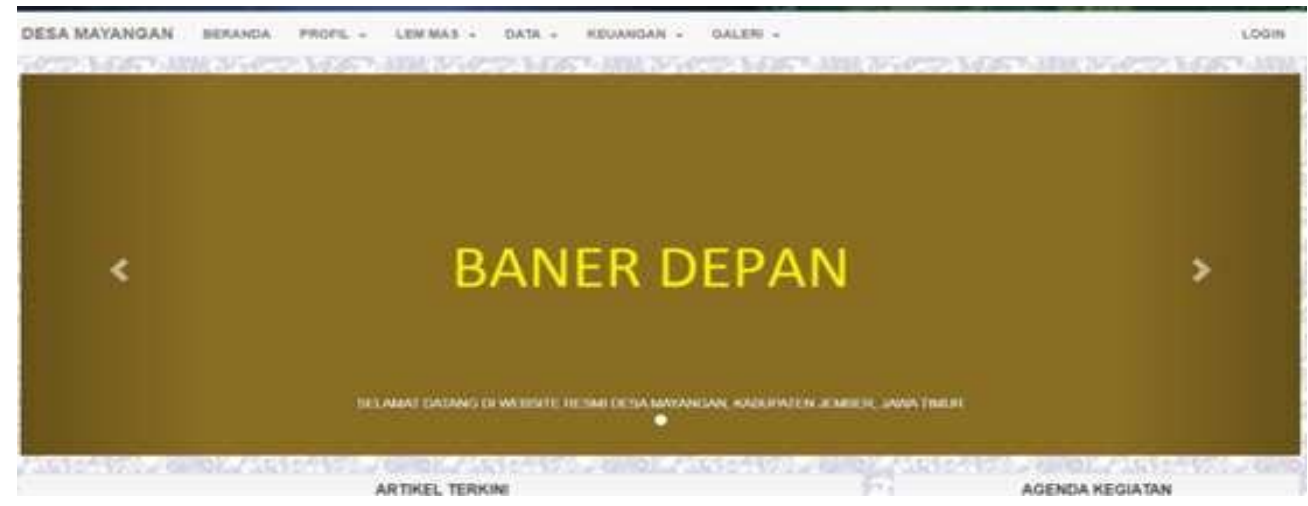

Gambar 1. Banner dan Slide Banner

b. Berita

Topata (2019) menjelaskan bahwa berita merupakan sebuah informasi yang sifatnya fakta yang sedang terjadi maupun sudah terjadi dan disampaikan melalui perantara media, baik itu media elektronik maupun mefia like cetak. Fitur ini dapat membantu menginformasikan hasil kegiatan atau peristiwa tertentu yang terjadi di desa saat ini kepada pengunjung website.

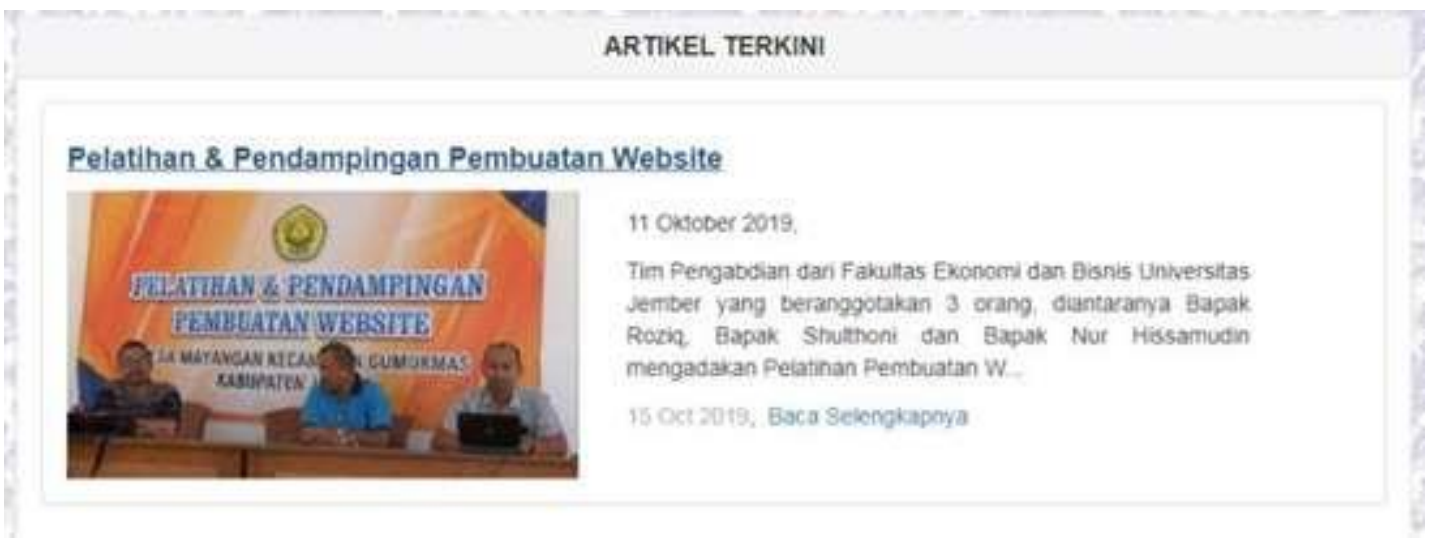

Gambar 2. Contoh Berita yang Ditampilkan di Website

c. Artikel

Kurniawan (2020) berpendapat bahwa artikel merupakan tulisan yang berisi pendapat, ide atau fakta yang mana kadang kala menghibur, mendidik ataupun mengkritisi yang disebar luaskan melalui media massa baik online maupun offline. Fitur ini dapat menambah nilai informasi yang dapat meramaikan suguhan informasi pada website. 


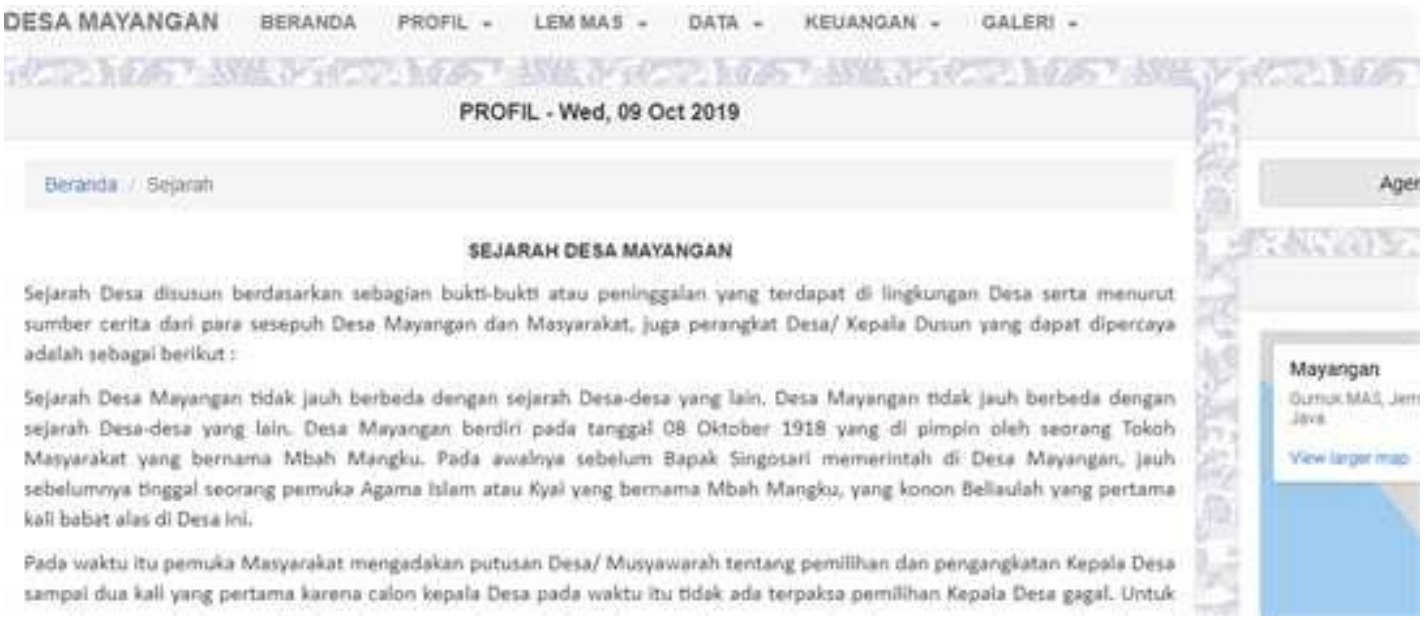

\section{Gambar 3. Artikel}

d. Agenda Kegiatan

Agenda kegiatan menurut Roziq dkk (2019) merupakan fitur yang berfungsi untuk memberikan informasi kegiatan Desa kepada pengunjung website, sehingga pengunjung tahu Acara, waktu dan tempat kegiatan yang akan diadakan oleh Desa.

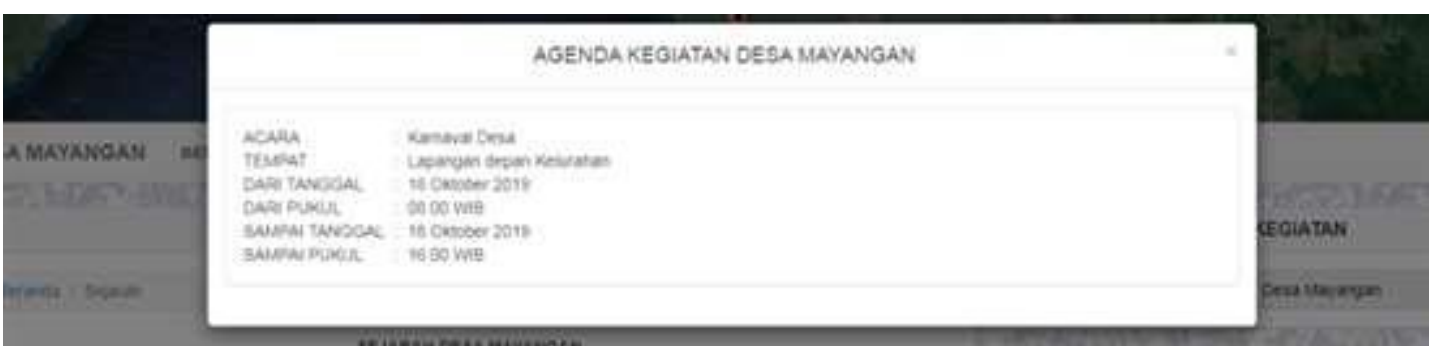

Gambar 4. Agenda Kegiatan

\section{e. Galeri Foto}

Galeri Foto akan menambah keramaian informasi pada website serta memiliki daya tarik tersendiri oleh pengunjung website yang ingin mengetahui penampakan secara visual Desa

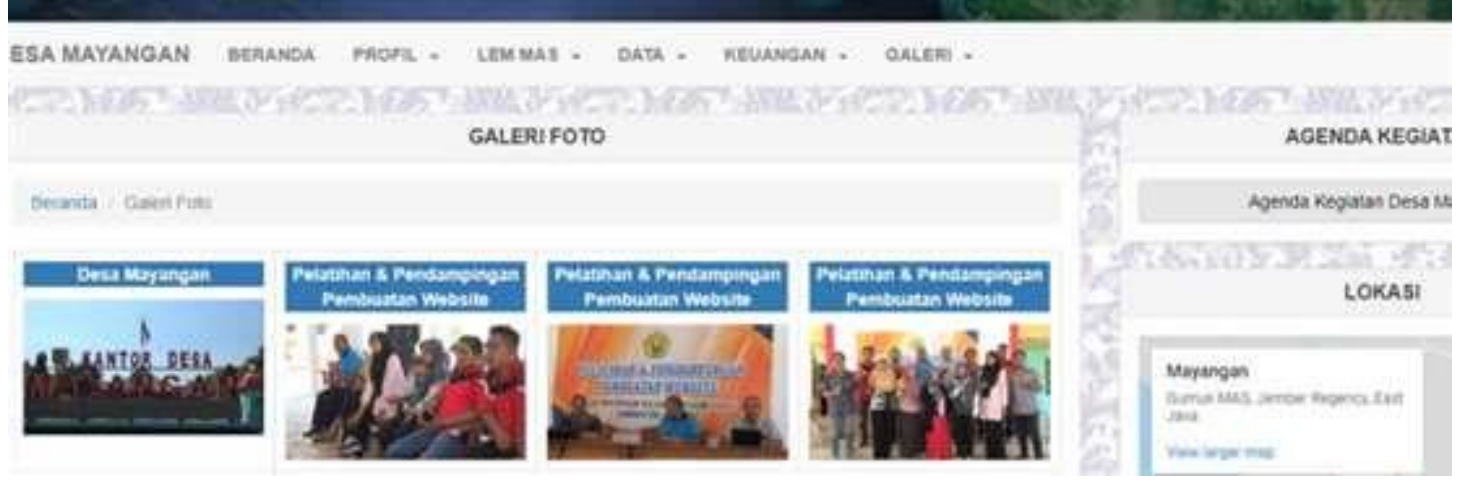

Gambar 4. Agenda Kegiatan 
f. Galeri Video

Galeri Video memberikan kemeriahan tertentu pada sebuah website serta memiliki daya tarik oleh pengunjung untuk melihat dan mengetahui informasi sesuai dengan konten yang di tampilkan.

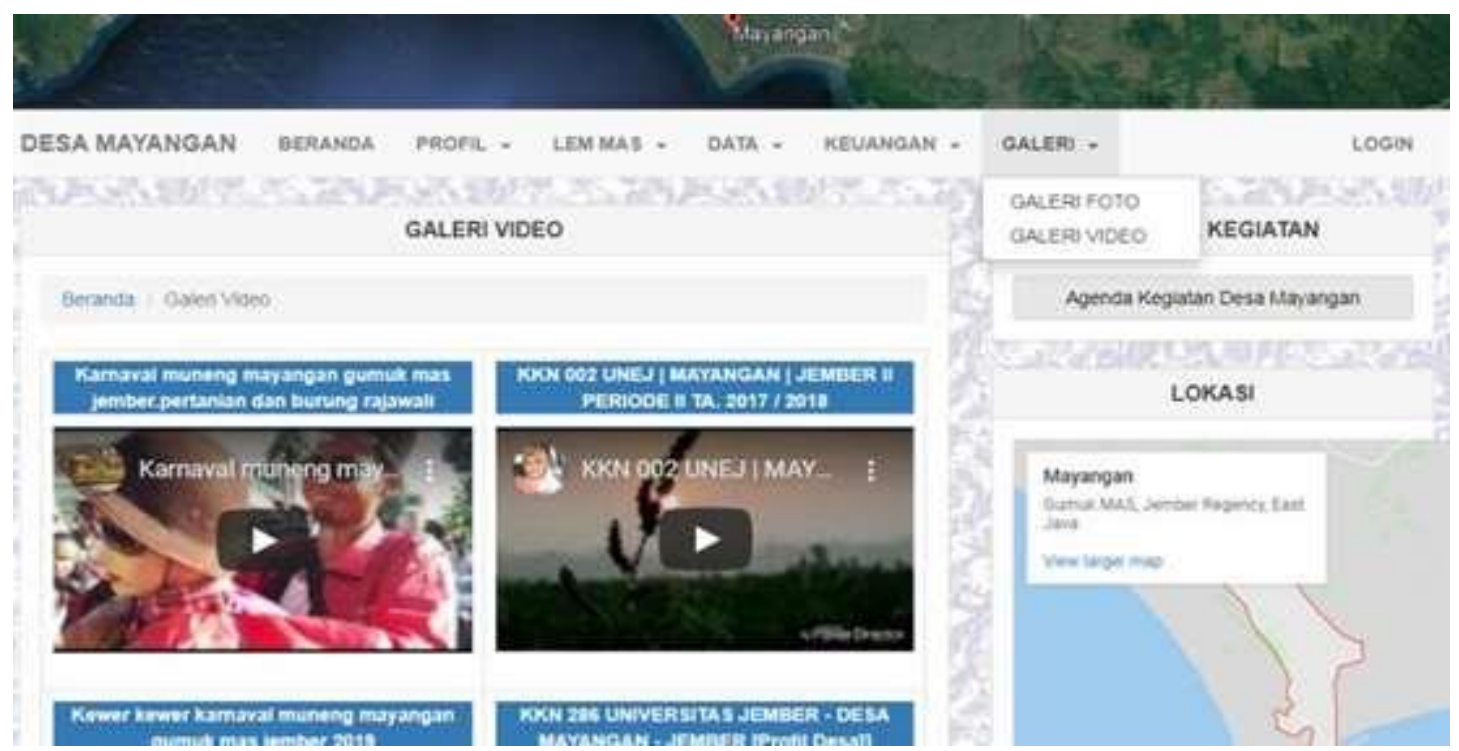

Gambar 6. Galeri Video

g. Informasi jumlah Pengunjung

Informasi jumlah pengunjung berfungsi sebagai bahan evaluasi bagi pengguna dalam pengembangan konten serta digunakan untuk menentukan prospek Website kedepannya.

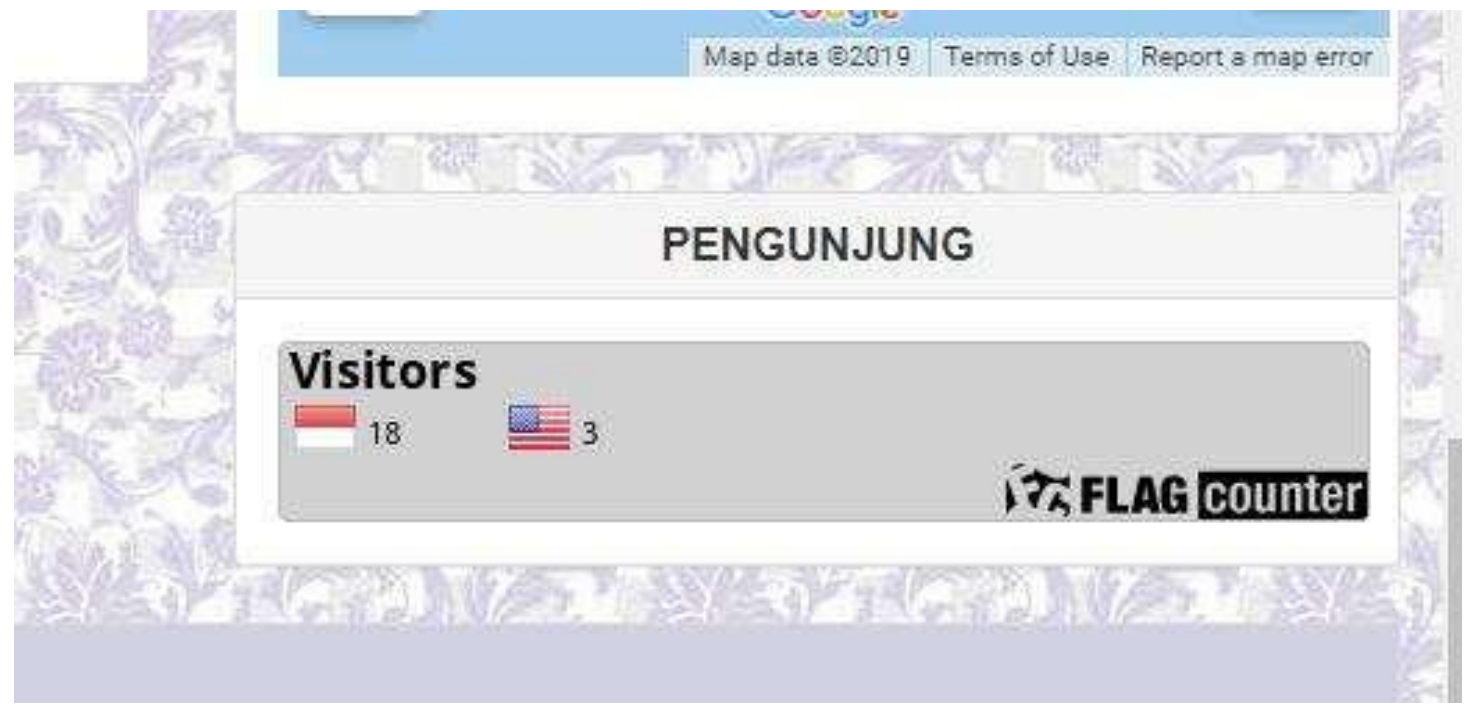

Gambar 7. Informasi Jumlah Pengunjung 
h. Informasi Detail (Footer)

Informasi pada Footer berfungsi sebagai tempat untuk menampilkan pintasan tertentu, kontak dan lain-lain.

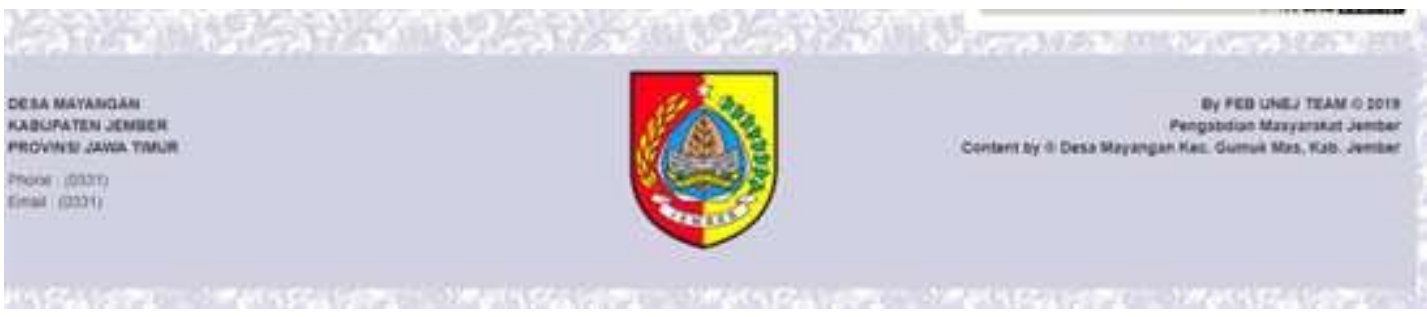

Gambar 8. Informasi Detail (Footer)

i. Login

Fitur login digunakan dengan alasan keamanan serta untuk keperluan pengembangan konten, mengatur user dan mengupdate informasi tertentu.

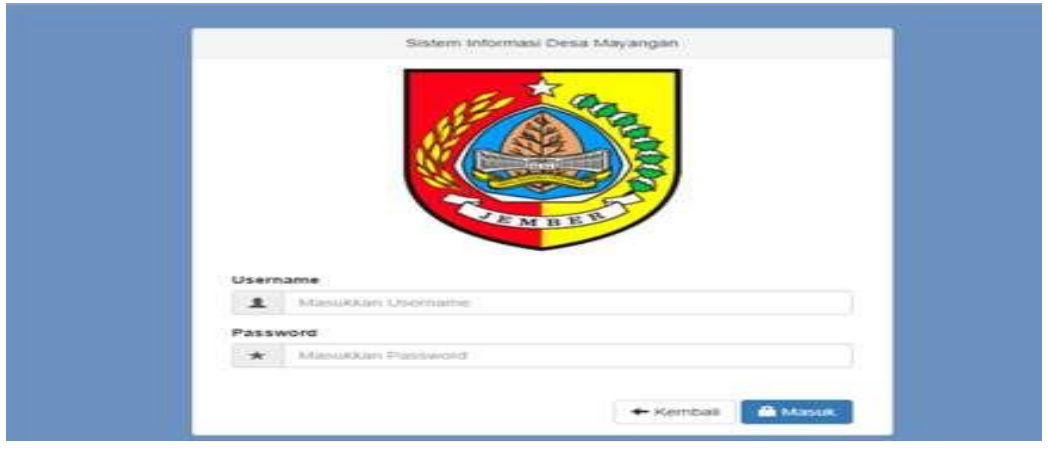

Gambar 9. Login

\section{KESIMPULAN}

Situs web Desa Mayangan, Kecamatan Gumukmas, Kabupaten Jember dibuat untuk menginformasikan berbagai sumber daya alam yang dapat dijadikan tujuan wisata. Informasi yang disajikan diharapkan memudahkan orang untuk bepergian. Situs web ini diharapkan dapat membantu meningkatkan promosi Desa Mayangan sehingga dapat berkembang, banyak pengunjung dan menumbuhkan kesejahteraan warga Mayangan. Situs web ini dapat membantu penduduk dan wisatawan dalam mencari informasi tentang Desa Mayangan. Hasil Pariwisata dan Produk di Desa Mayangan sekarang banyak dicari, dengan situs web dapat diberikan informasi dalam bentuk teks, gambar dan video. Warga dapat melakukan transaksi pemesanan untuk mengunjungi Desa Mayangan, transaksi dilakukan dari jarak jauh sehingga mudah dan ekonomis. Pada pengabdian selanjutnya diharapkan untuk fokus melakukan pembinaan dan penguatan produk dan wisata andalan yang ditampilkan di website, sehingga pengabdian di desa binaan Mayangan terus berkelanjutan.

\section{UCAPAN TERIMA KASIH}

Kami selaku Tim Pengabdian Fakultas Ekonomi dan Bisnis Universitas Jember mengucapkan banyak terima kasih kepada Lembaga Penelitian dan Pengabdian Masyarakat (LP2M) 
Universitas Jember yang telah memberikan kami dana pengabdian sebesar Rp 20.000.000,untuk mendukung kegiatan pengabdian kami di Desa Binaan Universitas Jember. Desa Binaannya terletak di Desa Mayangan Kecamatan Gumukmas Kabupaten Jember. Tidak lupa juga kami juga mengucapkan Kepala Desa Mayangan beserta perangkat Desa Mayangan yang telah memberikan waktu dan tenaga dalam kegiatan pembuatan Web Desa Mayangan. Harapan kami Desa Mayangan tidak hanya dikenal secara lokal tetapi juga dikenal ditingkat Nasional dari segi budaya, produk, dan pariwisatanya.

\section{DAFTAR PUSTAKA}

Kurniawan, Aris. 2020. Pengertian Artikel Adalah - Ciri, Fungsi,Tujuan, Jenis. Diunduh pada tanggal 29 September 2020 di https://www.gurupendidikan.co.id/pengertian-artikel/

Roziq, Ahmad, Moch. Shulthoni. dan Zainuri. Web Application As One Of The Supporting Promotion For Baznas Of Jember Regency. International Journal of Current Science and Engineering. Vol. 1. Issues 6. Pg 157-161.

Supriyanta, dan Khairun Nisa. 2015. Perancangan Website Desa Wisata Karangrejo Sebagai Media Informasi Dan Promosi. Jurnal Bianglala Informatika.Vol. 3. No. 1. Hal 35 - 40.

Topata, Jensen. 2019. Pengertian Berita: Jenis, Fungsi, Tujuan, Unsur dan Manfaatnya. Diunduh pada tanggal 29 September 2020 di www.mypurohith.com

Yolanda, Desta, Werman Kasoep, Dodon Yendri. 2018. Pembuatan dan Pelatihan Website BUMDes Desa Naras Hilir Kecamatan Pariaman Utara. Laporan Akhir Pengabdian Masyrakat. Universitas Andalas. 